\title{
Relação entre velocidade de deslocamento, rendimento da cana-de- açúcar e o consumo de combustível da colhedora
}

\author{
Murilo Battistuzzi Martins ${ }^{1}$, Carlos Renato Guedes $\operatorname{Ramos}^{1}$, Fábio Lopes de Souza ${ }^{1}$, Maria \\ Márcia Pereira Sartori ${ }^{1}$, Kléber Pereira Lanças ${ }^{1}$
}

\footnotetext{
${ }^{1}$ Universidade Estadual Paulista Júlio de Mesquita Filho - UNESP, Faculdades de Ciências Agronômicas - FCA, Campus de Botucatu, SP, Brasil. E-mail: mbm_martins@ hotmail.com, cramos@fca.unesp.br, fabiolopes.s@hotmail.com, mmpsartori@fca.unesp.br, kplancas@fca.unesp.br
}

Recebido: 22/09/2016; Aceito: 28/03/2017.

\section{RESUMO}

A colheita mecanizada de cana-de-açúcar apresenta diversos fatores que imprimem à essa atividade um custo elevado; dentre os principais fatores ressalta-se o consumo de combustível. O presente estudo teve como objetivo avaliar o consumo de combustível de uma colhedora de cana-de-açúcar em função da velocidade de deslocamento e do rendimento da cultura. $\mathrm{O}$ trabalho foi realizado em canaviais com produtividade de colmos de 65 e $80 \mathrm{t} \mathrm{ha}^{-1}$, sem a despalha prévia por fogo, com espaçamento entrelinhas de 1,5 m. Utilizou-se uma colhedora de cana-deaçúcar de uma linha, onde foi instalado dois fluxometros, para a medição do consumo instantâneo de combustível. Para aquisição dos dados foi usado um controlador lógico programável (CLP). O delineamento foi inteiramente casualizado em esquema fatorial $3 \times 2 \mathrm{com}$ seis repetições, sendo o primeiro fator constituído por três velocidades de deslocamento da colhedora $\left(2,5 \mathrm{~km} \mathrm{~h}^{-1} ; 3,5 \mathrm{~km} \mathrm{~h}^{-1}\right.$ e $\left.5,0 \mathrm{~km} \mathrm{~h}^{-1}\right)$ e o segundo fator por dois talhões de cana-de-

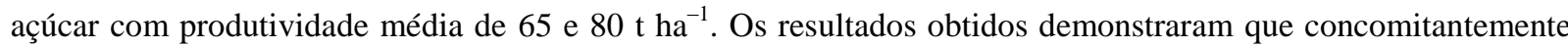
ao aumento da velocidade ocorreu aumento do consumo de combustível em litros por hora $\left(\mathrm{L} \mathrm{h}^{-1}\right)$, tanto para a produtividade de $65 \mathrm{t} \mathrm{ha}^{-1}$ como a de $80 \mathrm{t} \mathrm{ha}^{-1}$. Entretanto, o consumo de combustível por tonelada de colmos colhidos diminuiu com o aumento da velocidade da colhedora.

Palavras-chave: avaliação, desempenho, economia.

\section{Relationship between harvester speed, sugarcane yield and fuel consumption of harvester}

\begin{abstract}
The mechanized harvesting of sugarcane has several factors that make this activity has a high cost, and among the main ones is spending on fuel consumption. The study aimed to evaluate the fuel consumption of a harvester of sugarcane as affected by harvester speed and crop yield. The study was carried out in sugarcane fields with yield of 65 and $80 \mathrm{tha}^{-1}$ without the previous burning, with rows of $1.5 \mathrm{~m}$ spacing. In the harvester was installed two flowmeters for measuring the instantaneous fuel consumption. For the acquisition of the data it was used a programmable logic controller (PLC). The design was completely randomized in factorial scheme $3 \times 2$ with six replicates. The first factor is three harvester speed: $2.5 \mathrm{~km} \mathrm{~h}^{-1} ; 3.5 \mathrm{~km} \mathrm{~h}^{-1}$ and $5.0 \mathrm{~km} \mathrm{~h}^{-1}$ and the second factor is sugarcane yield. The results showed that as the speed increased, there is an increase in fuel consumption in liters per hour $\left(\mathrm{L} \mathrm{h}^{-1}\right)$ for both yields, $65 \mathrm{t} \mathrm{ha}^{-1}$ as an $80 \mathrm{t} \mathrm{ha}^{-1}$. However, the fuel consumption in liters per ton $\left(\mathrm{L} \mathrm{t}^{-1}\right)$ even with the increased speed there is a decrease in fuel consumption.
\end{abstract}

Key words: evaluation, performance, economy. 


\section{Introdução}

O Brasil é o maior produtor mundial de cana-deaçúcar, com área plantada na safra 2015/16 em torno de 8,7 milhões de hectares. Diversos fatores tem tornado o Brasil um país promissor para a exportação da cana-deaçúcar: o aumento da demanda mundial por etanol de fontes renováveis, a abertura de novos mercados na União Européia e o baixo estoque mundial que tem pressionado os preços. Tudo isso se alia às grandes áreas cultiváveis e condições edafoclimáticas favoráveis à cana-de-açúcar no Brasil. (CONAB, 2016).

A mecanização total da colheita de cana de açúcar é a opção que permite atender simultaneamente os requisitos ergonômicos, de viabilidade econômica e as exigências legais e ambientais atuais visto que se torna possível realizar a colheita sem queima prévia da canade-açúcar (BRAUNBECK; OLIVEIRA, 2006).

Entre os custos envolvidos para a produção da canade-açúcar tais como fertilizantes, mão de obra, agroquímicos; a colheita representa $30 \%$ devido ao alto consumo de combustível das colhedoras, que podem atingir de 50 a $60 \mathrm{~L} \mathrm{~h}^{-1}$ por máquina (RIPOLI; RIPOLI, 2009).

De acordo com Mialhe (1996), a mensuração da quantidade de combustível consumida, constitui um dos mais importantes aspectos da avaliação do rendimento de um motor. Segundo Lanças (2012), o consumo de combustível de colhedoras de cana de açúcar deve ser mensurado e avaliado durante a colheita efetiva. Assim, este trabalho objetivou avaliar o consumo de combustível de uma colhedora de cana-de-açúcar em função da velocidade de deslocamento e do rendimento de colmos da cultura.

\section{Material e Métodos}

O trabalho foi realizado em canaviais em produção sem a queima prévia, com produtividade média de 65 e $80 \mathrm{t} \mathrm{ha}^{-1}$ respectivamente. O espaçamento adotado foi de 1,5 m entre fileiras. Utilizou-se uma colhedora de cana-de-açúcar de uma linha da marca Case IH, modelo A8800 com potência no motor de $330 \mathrm{cv}(243 \mathrm{kw})$, durante o processo de colheita.

O consumo de combustível por hora $\left(\mathrm{L} \mathrm{h}^{-1}\right)$ foi mensurado utilizando dois fluxômetros volumétricos com capacidade máxima de leitura de $500 \mathrm{~L} \mathrm{~h}^{-1}$ e razão de 1 pulso elétrico para cada $10 \mathrm{ml}$, sendo um instalado na entrada da bomba injetora do motor da colhedora e o outro no retorno do combustível ao tanque. O consumo real foi calculado pela diferença entre os valores dos pulsos gerados pelos fluxômetros na entrada da bomba injetora e do retorno ao tanque de combustível. O cálculo do consumo horário de combustível foi obtido com a equação 1 :

$$
C h=\left(\frac{\sum(p e-p s) \times 3,6}{\Delta t}\right) \times 10
$$

Onde:

$C C h=$ consumo por hora de combustível $\left(\mathrm{L} \mathrm{h}^{-1}\right)$

$\boldsymbol{\Sigma}(p \mathrm{e}-p s)=$ diferença entre os somatórios de pulsos dos fluxômetros, correspondendo ao combustível gasto $(\mathrm{mL})$, de entrada e de saída;

$\Delta \mathrm{t}=$ tempo gasto $(\mathrm{s})$;

3,6 = fator de conversão;

10 = razão entre pulsos gerados pelo fluxômetro e o volume de combustível medido.

Para aquisição dos dados gerados pelos fluxômetros, utilizou-se um controlador lógico programável (CLP), que foi instalado na cabine da colhedora. O mesmo faz a leitura e armazenamento dos dados enviados pelos fluxômetros. Os dados adquiridos pelo CLP foram utilizados posteriormente para cálculo do consumo de combustível durante a colheita mecanizada.

A determinação do consumo de combustível por tonelada de cana colhida $\left(\mathrm{L} \mathrm{t}^{-1}\right)$ foi estimada coma equação (2):

$C t=C C a / P$

Onde:

$C t=$ consumo de combustível por toneladas de cana colhida $\left(\mathrm{L} \mathrm{t}^{-1}\right)$

$C C a=$ consumo de combustível por área $\left(\mathrm{L} \mathrm{ha}^{-1}\right)$

$P=$ produtividade do canavial $\left(\mathrm{t} \mathrm{ha}^{-1}\right)$

As parcelas experimentais eram compostas de 100 metros de comprimento, as quais foram determinadas utilizando um receptor Global Navigation Satellite System (GNSS) modelo Garmin 60 CSx. O delineamento foi inteiramente casualizado em esquema fatorial $3 \times 2$, sendo o primeiro fator três velocidades de 2,5 $\mathrm{km} \mathrm{h}^{-1} ; 3,5 \mathrm{~km} \mathrm{~h}^{-1}$ e $5,0 \mathrm{~km} \mathrm{~h}^{-1}$ e o segundo fator duas produções 65 e $80 \mathrm{tha}^{-1}$.

Os dados foram submetidos à análise de variância; as médias relativas às velocidades de colheita foram comparadas pelo teste Tukey e as médias relativas a produtividade foram comparadas pelo teste F. Em ambos os testes utilizou-se a porcentagem de $5 \%$ de probabilidade.

\section{Resultados e Discussão}

A Tabela 1 apresenta os valores de consumo de combustível em litros por hora $\left(\mathrm{L} \mathrm{h}^{-1}\right)$ no momento da colheita em área com produtividade média de 80 tonelada por hectare $\left(80 \mathrm{t} \mathrm{ha}^{-1}\right)$ e de 65 toneladas por hectare $\left(65 \mathrm{t} \mathrm{ha}^{-1}\right)$ nas diferentes velocidades de deslocamento $\mathrm{Na}$ Tabela 2 são apresentados os resultados de consumo de combustível da colhedora de cana-de-açúcar em litros por tonelada de cana colhida $\left(\mathrm{L} \mathrm{t}^{-1}\right)$ durante a realização do experimento. 
Tabela 1. Valores médios de consumo de combustível por hora $\left(\mathrm{L} \mathrm{h}^{-1}\right)$.

\begin{tabular}{ccccc}
\hline \multirow{2}{*}{$\begin{array}{c}\text { Produtividade } \\
\left.(\mathrm{t} \mathrm{ha})^{-1}\right)\end{array}$} & \multicolumn{3}{c}{$\begin{array}{c}\text { Velocidade de deslocamento } \\
\left(\mathrm{km} \mathrm{h}^{-1}\right)\end{array}$} & \multirow{2}{*}{ Média } \\
\cline { 2 - 4 } & 2,5 & 3,5 & 5,0 & \\
\hline 65 & 42,23 & 42,16 & 47,57 & $44,0 \mathrm{~A}$ \\
80 & 38,46 & 42,25 & 46,81 & $42,0 \mathrm{~A}$ \\
Média & $40,3 \mathrm{~b}$ & $42,2 \mathrm{~b}$ & $47,2 \mathrm{a}$ & \\
\hline Fonte de variação & \multicolumn{3}{c}{ Valor de $\mathrm{F}$} \\
\hline Velocidade (V) & \multicolumn{3}{c}{$22,76^{*}$} \\
Produtividade (P) & $2,99^{\mathrm{NS}}$ & \\
Interação V x P & \multicolumn{2}{c}{$1,87^{\mathrm{NS}}$} & \\
\hline CV (\%) & \multicolumn{3}{c}{8,17} \\
\hline
\end{tabular}

Médias seguidas de letras iguais maiúsculas na coluna não diferem entre si pelo teste $\mathrm{F}(\alpha=5 \%)$, médias seguidas de letras iguais maiúsculas na linha não diferem entre si pelo teste de Tukey $(\alpha=5 \%)$.

Tabela 2. Valores médios de consumo de combustível por tonelada de cana-de-açúcar colhida $\left(\mathrm{L} \mathrm{t}^{-1}\right)$

\begin{tabular}{ccccc}
\hline \multirow{2}{*}{$\begin{array}{c}\text { Produtividade } \\
\left(\mathrm{t} \mathrm{ha}^{-1}\right)\end{array}$} & \multicolumn{3}{c}{$\begin{array}{c}\text { Velocidade de deslocamento } \\
\left(\mathrm{km} \mathrm{h}^{-1}\right)\end{array}$} & \multirow{2}{*}{ Média } \\
\cline { 2 - 4 } & 2,5 & 3,5 & 5,0 & \\
\hline 65 & 1,7 & 1,2 & 1,0 & $1,3 \mathrm{~A}$ \\
80 & 1,3 & 1,0 & 0,8 & $1,0 \mathrm{~B}$ \\
Média & $1,5 \mathrm{a}$ & $1,1 \mathrm{~b}$ & $0,9 \mathrm{c}$ & \\
\hline Fonte de variação & \multicolumn{3}{c}{ Valor de $\mathrm{F}$} \\
\hline Velocidade (V) & \multicolumn{3}{c}{$113,15^{*}$} \\
Produtividade (P) & \multicolumn{3}{c}{$84,81^{*}$} & \\
Interação V x P & $2,06^{\mathrm{NS}}$ & \\
\hline CV (\%) & & 24,58 \\
\hline
\end{tabular}

Médias seguidas de letras iguais maiúsculas na coluna não diferem entre si pelo teste $\mathrm{F}(\alpha=5 \%)$, médias seguidas de letras iguais maiúsculas na linha não diferem entre si pelo teste de Tukey $(\alpha=5 \%)$.

O aumento ou redução na velocidade de deslocamento no momento da colheita de cana-deaçúcar, pode ocorrer por diversos fatores que influenciam diretamente no consumo de combustível como falhas no canavial, topografia da área, acamamento de plantas, experiência do operador, fatores ambientais. Giachini et al. (2016) em estudo que estabeleceu o consumo de combustível e perdas de cana-de-açúcar durante a colheita diurna e noturna, observou variações no consumo de combustível durante a colheita mecanizada da cultura em diferentes turnos de trabalho. Vale ressaltar que pode haver variações entre os diferentes turnos de colheita e na forma da operação.

Segundo Banchi et al. (2012), calcular o consumo médio de combustível por hora pode aparentar uma falsa vantagem quando o valor de consumo diminui ao longo do tempo. No entanto, ocorre o inverso quando o consumo por tonelada colhida é analisada.

O consumo médio de combustível por tonelada de cana-de-açúcar diminuiu com o aumento da velocidade, sendo verificado maior consumo de combustível à uma velocidade de deslocamento de $2,5 \mathrm{~km} \mathrm{~h}^{-1}$ em relação à velocidade de $5,0 \mathrm{~km} \mathrm{~h}^{-1}$. Assim como as médias de produtividade cujo maior consumo de combustível por tonelada colhida foi observado no talhão com produtividade de $65 \mathrm{t} \mathrm{ha}^{-1}$.

Com o aumento da velocidade de deslocamento da colhedora, maior quantidade de cana-de-açúcar é colhida, consequentemente, com o aumento da quantidade de cana-de-açúcar colhida, o custo de combustível por tonelada diminui, conforme Testa (2016) em avaliação do desempenho operacional e energético de colhedoras de cana-de-açúcar para uma e duas linhas da cultura.

Os resultados deste ensaio são superiores ao de Ramos et al (2016) em análise do consumo de combustível de uma colhedora de cana-de-açúcar em diferentes configurações de operação, sendo que a variação na rotação do motor da máquina não influenciou no consumo de combustível por tonelada colhida; já o aumento da velocidade de deslocamento reduziu o consumo por tonelada.

De acordo com Peloia et al. (2010), estudos sobre mecanização promovem melhorias nas operações e reduzem custos, uma vez que a utilização de baixas velocidades podem inviabilizar o uso de colhedoras, devido à redução da capacidade de colheita.

\section{Conclusões}

O aumento da velocidade de deslocamento da colhedora resulta em menor consumo de combustível por tonelada de cana-de-açúcar colhida; no entanto, há aumento no consumo médio de combustível por hora.

\section{Referências Bibliográficas}

BANCHI, A. D.; LOPES, J. R.; MARTINS, J. M. S.; DIMASE, M. Capacidade operacional de colhedoras de canade-açúcar - Modelagem matemática em função da produtividade agrícola e da vida da máquina. Revista Agrimotor, São Paulo-SP, v. 09, n. 77, p. 42-45, 2012.

BRAUNBECK, O. A.; OLIVEIRA, J. T. A. Colheita de canade-açúcar com auxílio mecânico. Revista Engenharia Agrícola, Jaboticabal-SP, v. 26, n. 01, p. 300-308, 2006.

CONAB. COMPANHIA NACIONAL DE ABASTECIMENTO. Acompanhamento da safra brasileira, segundo levantamento - safra 2016/2017 - agosto/2016. Brasília-DF, 2016. Disponível em: <http://www.conab.gov.br>. Acesso em: 08 setembro 2016.

GIACHINI, C. F.; RAMOS, C. R. G.; LYRA, G. A.; GAMERO, C. A.; LANÇAS, K. P. Consumo de combustível e perdas de cana-de-açúcar durante a colheita diurna e noturna. Energia na Agricultura, Botucatu-SP, v. 31, n. 01, p. 10-16, 2016.

LANÇAS, K. P. Consumo de combustível: Não se engane. In: FIORESE, D. A.; LANÇAS, K. P.; GUERRA, S. P. S.; MARASCA, I.; ALEIXO, E. V.; MACIEL, A. J. S. Características energéticas dos tratores agrícolas. Revista Agriworld, Bragança Paulista-SP, v. 04, n. 10, p. 38-46, 2012. 
LYRA, G.; MASIERO, F. C.; LANÇAS, K. P.; RAMOS, C. R. G.; GIACHINI, C. Velocidade $x$ Consumo. Revista Cultivar Máquinas, Pelotas-RS, v. 06, n. 164, p. 28-30, 2016.

MIALHE, L. G. Máquinas agrícolas: ensaios \& certificação. Piracicaba-SP: FEALQ, 1996. 722p.

PELOIA, P. R.; MILAN, M.; ROMANELLI, T. L. Capacity of the mechanical harvesting process of sugarcane billets. Scientia Agrícola, Piracicaba-SP, v. 67, n. 06, p. 619-623, 2010.

RAMOS, C. R. G.; LANÇAS, K. P.; LYRA, G. A.; SANDI, F. Fuel consumption of a sugarcane harvester in different operational settings. Revista Brasileira de Engenharia Agrícola e Ambiental, Campina Grande-PB, v. 20, n. 6, p. 588-592, 2016.
RIPOLI, T. C. C.; RIPOLI, M. L. C. Biomassa de cana-deaçúcar: colheita, energia e ambiente. Piracicaba-SP: PLD, 2009. 333p.

TESTA, J. V. P.; LANÇAS, K. P.; MARTINS, M. B.; SANDI, F.; DRUDI, F. S. Desempenho operacional e energético de colhedoras de cana-de-açúcar (Saccharum spp.) para uma e duas linhas da cultura. Revista Energia na Agricultura, Botucatu-SP, v. 31, n.3, p.253-258, 2016. 